\title{
Empreendedorismo e conservação ambiental no interior de São Paulo
}

Eduardo Ehlers*

Resumo: Na década passada duas centenas de municípios paulistas ampliaram suas áreas de Mata Atlântica, sendo que a maioria deles concentra-se em territórios contíguos formando verdadeiras manchas de recuperação florestal no mapa do estado. Este artigo discute os principais determinantes que explicam este inusitado aumento. A suposição inicial era de que a recuperação da Mata Atlântica estaria associada ao avanço dos empreendimentos que valorizam o patrimônio natural e que promovem o seu aproveitamento econômico. Conclui-se que o cumprimento da legislação, decorrente da fiscalização mais rigorosa, e a retração das atividades agropecuárias, que permite a regeneração natural das matas, foram os principais determinantes dessa recuperação. Todavia, como suposto inicialmente, em alguns territórios paulistas já se nota uma rara combinação entre empreendedorismo e conservação florestal. Essa sinergia não surge ao acaso; depende, em grande parte, da existência de arranjos institucionais entre atores públicos e privados interessados na conservação do patrimônio natural.

Palavras-chave: desenvolvimento rural, amenidades rurais, Mata Atlântica, instituições.

Classificação JEL: Q23

*Doutor em Ciência Ambiental pela Universidade de São Paulo e Diretor de Graduação do Centro Universitário Senac. eduardoehlers@sp.senac.br 
Abstract: Over the last decade, some two hundred municipalities in the state of São Paulo increased the area of Atlantic Forest, and since most of them are adjacent areas they are starting to show up as authentic spots of recovering forests on the map of the State. The present article seeks to identify the major factors underpinning this unprecedented increase. The initial premise was that the recovery of the Atlantic Forest was associated with the increasing number of ventures protecting natural heritage and promoting its economic exploitation. The study shows that compliance with the legislation, resulting from enhanced enforcement, along with a reduction in farming and livestock-breeding activities that allowed the natural growth of the vegetation, were the main drivers of the recovery of the Atlantic Forest over the last decade. However, as initially assumed, a rare combination of private enterprise and forest conservation can be witnessed in some areas of São Paulo State. This synergy has not arisen by chance; it mainly depends on the existence of institutional agreements among public and private players committed to the conservation of the natural heritage.

Key words: rural development, rural amenities, Atlantic Forest, institutions.

JEL Classification: Q23

\section{Introdução}

O debate sobre o desenvolvimento no meio rural expõe, claramente, duas posições antagônicas em relação à conservação dos recursos naturais. Em um extremo, a convicção de que a natureza é um obstáculo a ser removido para dar lugar ao progresso, particularmente ao progresso da agricultura moderna. No outro, a visão oposta de que determinadas atividades que promovem o aproveitamento econômico do patrimônio natural podem, justamente, estimular o desenvolvimento. Mas será mesmo possível conciliar crescimento e conservação?

Analisando-se a trajetória do crescimento econômico do Estado de São Paulo a resposta a esta indagação só pode ser negativa. No início do século passado, o sucesso das lavouras cafeeiras se devia, em grande parte, à fertilidade dos solos gerada pela queima da Floresta Atlântica. 
A euforia das grandes safras não durou mais do que duas ou três décadas, até que as camadas mais férteis dos solos fossem carregadas pela erosão. O declínio do ciclo do café coincidiu com o avanço das indústrias e com a expansão da malha ferroviária, que tinham como matriz energética a lenha e o carvão vegetal provenientes das florestas nativas. Esses dois importantes impulsos econômicos ajudaram São Paulo a receber o apelido de "locomotiva do País", mas, ao mesmo tempo, eliminaram quase toda a Mata Atlântica do estado.

Mais recentemente, entre 1990 e 1995, a área de Mata Atlântica perdeu mais 3,6\% de sua extensão. Entretando, contrariando a tendência histórica, em 85 municípios a área de mata aumentou nesse período. Na segunda metade da década, essa tendência se repetiu: entre 1995 e 2000, a Mata Atlântica encolheu mais 1,7\% em todo o estado, mas em 131 municípios o aumento das áreas de mata superou as perdas. Ao todo, 204 municípios paulistas ampliaram suas áreas de mata na primeira ou na segunda metade da década passada, sendo que 12 deles aparecem nas duas listas, isto é, tiveram saldo positivo nos dois períodos analisados.

O que teria afetado a histórica tendência de degradação da Mata Atlântica paulista e provocado esse inusitado aumento? O presente artigo discute esta questão, partindo da hipótese de que a recuperação da Mata Atlântica estaria associada ao avanço dos empreendimentos que valorizam o patrimônio natural e que promovem o seu aproveitamento econômico.

\section{Metodologia}

A pesquisa teve início a partir da revisão da produção científica sobre a importância ecológica e econômica da biodiversidade; sobre os principais fatores que vêm provocando sua degradação; e sobre as novas feições do desenvolvimento no meio rural. Ficou evidente que já está em curso uma nova fase de desenvolvimento baseada em atividades econômicas que exploram um dos principais trunfos do meio rural: a possibilidade de um relacionamento mais próximo à natureza. Nessa fase, é crucial o papel dos empreendedores que criam novos negócios relacionados ao aproveitamento das amenidades rurais, tornando-se importantes agentes na conservação do patrimônio natural. 
Essa constatação evidenciou a necessidade de se compreender o fenômeno do empreendedorismo e sua relação com o desenvolvimento. Dentre os autores que tratam deste tema, o mais conhecido é o economista austríaco Joseph Schumpeter (SCHUMPETER, 1961 [1934]). Sua teoria sobre o desenvolvimento capitalista destaca o papel do empreendedor na introdução de inovações, as quais permitem superar velhas "combinações”, favorecendo o crescimento econômico. Certamente, os empreendedores que iniciam novos negócios relacionados à valorização das amenidades rurais introduzem inovações no modo de utilização dos recursos (naturais), as quais provocam mudanças nas dinâmicas econômicas.

Dentre os fatores recorrentes que influenciam o grau de empreendedorismo de determinado território destacam-se: (1) a idade da população, os mais jovens tendem a ser mais empreendedores; (2) a localização, as áreas urbanas em geral têm mais negócios do que as rurais; (3) o nível de desemprego, quanto mais alto, maior o número de empreendedores; (4) a disponibilidade de recursos; (5) o nível educacional; (6) e, por fim, a parcela da população com casa própria, pois a posse de um imóvel muitas vezes serve como ponto de partida para a abertura de um novo negócio (OCDE, 1998:92).

As vantagens competitivas de determinado território decorrem de diferenças nas estruturas econômicas, culturais, históricas e institucionais. Michael Porter investiga a relação entre empreendedorismo e a concentração de firmas, fenômeno conhecido como clustering, ou formação de "feixes". "Os competidores em muitas indústrias de sucesso internacional - e, com freqüência, em grupos inteiros de indústrias - estão muitas vezes localizados numa única cidade ou numa única região dentro de um país” (PORTER, 1989:186). Basicamente, os negócios localizados em clusters, ou arranjos produtivos, obtêm vantagens competitivas derivadas de ações conjuntas ou de economias externas locais.

Mesmo não havendo consenso na comunidade científica, a noção de cluster pode ser definida como:

“(...) uma concentração geograficamente delimitada de negócios independentes que se comunicam, dialogam e transacionam para partilhar coletivamente tanto de oportunidades quanto de ameaças, gerando novos conhecimentos, concorrência inovadora, 
chances de cooperação, adequada infra-estrutura, além de freqüentemente também atraírem os correspondentes serviços especializados e outros negócios correlacionados” (VEIGA, 2000:13).

Mas seria ingênuo acreditar que a simples abertura e concentração de novos negócios em determinados territórios poderia garantir o que vem sendo chamado de "uso sustentável" das florestas e dos demais recursos naturais. Mesmo sendo impossível fazer qualquer tipo de generalização, a principal explicação para as situações exitosas aponta para a existência de arranjos institucionais que conduzam à formulação de normas claramente definidas e de mecanismos que permitam regular o acesso aos recursos de uso comum. A necessidade de se compreender esses arranjos não pode prescindir da análise das regras que levam cada sociedade a conservar ou a degradar seus recursos. Não pode prescindir, portanto, do conhecimento das instituições.

As instituições podem ser entendidas como as regras que permeiam o convívio e determinam o comportamento dos indivíduos em uma sociedade. É a existência de um conjunto de regras claramente definidas, e de mecanismos que garantam seu cumprimento, que condiciona ambientes mais favoráveis às relações sociais e às ações cooperativas. Por isso, as instituições, formais ou informais, são consideradas cruciais para o desempenho econômico e para o desenvolvimento das nações.

A origem do institucionalismo é atribuída a pensadores do início do século XX, como Thorstein Veblen, John R. Commons e Wesley Mitchel, principais expoentes da vertente que ficou conhecida como o "velho" institucionalismo norte-americano (CONCEIÇÃO, 2000:86). Entretanto, diante do predomínio do pensamento neoclássico, estas idéias ficaram em segundo plano durante quase todo o século. Foi só a partir da década de 1980 - talvez devido ao que Thomas Kuhn (KUHN, 1995 [1962]) consideraria o aparecimento de "anomalias" do paradigma predominante - que as teorias institucionalistas foram ressuscitadas e a produção científica reativada.

A maioria das abordagens institucionalistas questiona importantes pilares do pensamento neoclássico, como a crença de que o mercado pode regular o equilíbrio da economia. Para os institucionalistas uma das principais falhas dos neoclássicos consiste em tratar os indivíduos 
como seres independentes, cujas preferências são determinadas por sua racionalidade. É como se todas as decisões do mercado fossem embasadas por escolhas racionais com vistas à maximização (KUTTNER, 1998:70). Entretanto, a motivação dos agentes é bem mais complicada do que se imagina na teoria neoclássica. O ser humano nem sempre maximiza as riquezas: muitas vezes suas escolhas são determinadas por valores, por crenças, por reações altruístas ou mesmo pela imposição de auto-restrições.

Em contraposição ao pensamento neoclássico, os institucionalistas consideram que os indivíduos são interdependentes e que seus instintos, seus hábitos e suas crenças exercem um papel fundamental na evolução econômica. Consideram, também, que a economia de mercado é regida pelas ações coletivas e que para entender os processos econômicos é necessário adotar abordagens interdisciplinares, levando-se em conta aspectos políticos, sociais e culturais. O importante é entender como ocorrem as mudanças, os processos de inovação e o conseqüente crescimento econômico.

Isso significa, então, que institucionalismo é uma oposição à teoria neoclássica? Ou, ao contrário, seria uma espécie de evolução deste pensamento? Pelo visto, a maioria dos institucionalistas ficaria com a primeira opção, mas no estágio em que se encontra este debate é possível abrigar sob a mesma noção desde abordagens marxistas até aquelas que poderiam ser consideradas uma espécie de aprimoramento do pensamento econômico neoclássico. E, por enquanto, não parece haver na comunidade científica um consenso sobre qual seria a melhor "taxonomia" das teorias institucionalistas.

Douglass North, prêmio Nobel em 1993, é um dos principais autores do ressurgimento da economia institucional, ou nova economia institucional, ocorrido nas décadas de 1980 e 1990. Sua análise orienta-se, principalmente, ao entendimento dos grandes movimentos sociais que tornam possíveis as transações econômicas, investigando os fatores que promovem as mudanças nas organizações e nas instituições. Para o autor, as instituições podem ser definidas como as restrições criadas pelos seres humanos que acabam determinando as suas relações. Ao fornecer uma estrutura para a vida cotidiana, as instituições reduzem as incertezas e, conseqüentemente, os custos de 
transação. Assim, afetam tanto as transações sociais como o desempenho da economia (NORTH, 1981; 1990).

O pensamento institucionalista não se limita à adoção de um modelo geral e simplificado de interpretação da realidade. Ao contrário, além dos elementos essencialmente econômicos, contempla a análise das variáveis políticas, sociais e culturais, o que o torna extremamente atraente aos pesquisadores que trafegam por diferentes áreas de conhecimento, como é o caso dos que atuam na interface meio ambiente e desenvolvimento. Dentre os institucionalistas, Elinor Ostrom (OSTROM, 1986; 1990; 2001) é quem mais se dedica à compreensão dos mecanismos de controle criados pelos grupos para o manejo de recursos de uso comum. Sua principal contribuição está nas explicações sobre a evolução das instituições e sua relação com as ações coletivas. Suas teses serviram de base teórica para o estudo da formação de arranjos institucionais favorávies à conservação da Mata Atlântica paulista.

Em resumo, foi a partir das reflexões surgidas dessa revisão da literatura científica e da constatação de que cerca de 200 municípios paulistas ampliaram suas áreas de Mata Atlântica na década de 1990 que emergiu o problema científico e a hipótese de uma tese de doutorado, cujas principais conclusões são resumidas neste artigo.

Os procedimentos de coleta de dados empíricos que permitiram o teste da hipótese foram divididos em três etapas. A primeira etapa consistiu em uma análise da variação da cobertura florestal Atlântica nos seguintes conjuntos de municípios: (1) nos que tiveram maiores variações de população entre 1991 e 2000; (2) nos que mais concentram agricultores com certificação orgânica e biodinâmica; (3) nos municípios que possuem unidades de conservação estaduais; (4) nas estâncias turísticas, climáticas, balneárias, hidrominerais e nos pólos de ecoturismo definidos pela Embratur (Empresa Brasileira de Turismo); (5) e nos municípios com elevada densidade de Microempresas e de Empresas de Pequeno Porte (MEPP) formalmente constituídas.

Na segunda etapa foram coletadas informações em visitas realizadas a dez municípios com mais elevada densidade de MEPP no Estado de São Paulo e em entrevistas com prefeitos, secretários, técnicos das prefeituras e empreendedores desses municípios. Essas visitas tinham dois objetivos: (1) o primeiro era o de identificar, tanto os principais fa- 
tores que contribuíram para a elevada densidade de empreendimentos, como as atividades que vêm motivando a abertura de novos negócios; (2) o segundo objetivo era o de verificar se a existência de microempresas e de empresas de pequeno porte se deve a algum tipo de inovação em relação ao aproveitamento do patrimônio natural ou das amenidades rurais presentes nesses municípios.

Na terceira etapa foram entrevistados representantes dos municípios que ampliaram a Mata Atlântica nos períodos de 1990 a 1995 e de 1995 a 2000. O objetivo era, não apenas, conhecer os fatores, espontâneos ou induzidos, que explicam a expansão dos fragmentos florestais, como também, relacionar esses fatores à hipótese da pesquisa. Esses dados geraram dois tipos de informação sobre os períodos de 1990-1995 e 1995-2000: (1) as razões que levaram ao aumento da cobertura florestal no conjunto de municípios; (2) os principais motivos que explicam o aumento da Mata Atlântica nas concentrações de municípios denominadas como manchas de recuperação florestal. Foram estudadas, particularmente, as manchas nas quais se formam nítidos arranjos locais em torno do aproveitamento econômico do patrimônio natural ${ }^{1}$.

Os resultados sistematizados a partir dessas entrevistas não podem, porém, ser entendidos como uma tradução exata dos determinantes que contribuíram para a recuperação das áreas de Floresta Atlântica em cada município. O nível de informação dos entrevistados era variável e os depoimentos, muitas vezes, permeados por nítidas interpretações subjetivas de cunho político ou pessoal. Com o intuito de ampliar a consistência dessas informações foram realizadas entrevistas com especialistas, principalmente do governo do estado, e visitas in locu a 20 municípios que tiveram aumento de Mata Atlântica nos dois períodos analisados ${ }^{2}$.

\footnotetext{
${ }^{1}$ Na Serra da Mantiqueira, no Circuito das Águas e na região conhecida como Cuestas, na parte central do Estado de São Paulo.

${ }^{2}$ Foram visitados: Águas de Lindóia, Amparo, Bananal, Brotas, Corumbataí, Cunha, Dourado, Itirapina, Joanópolis, Lindóia, Luis Antonio, Monteiro Lobato, Morungaba, Serra Negra, Santo Antonio Jardim, São Bento do Sapucaí, São José do Barreiro, São Luis do Paraitinga, Silveiras e Socorro.
} 


\section{Resultados e Discussão}

\subsection{Determinantes da variação da cobertura florestal atlântica}

No Estado de São Paulo, entre 1990 e 1995, a Mata Atlântica foi reduzida em 3,6\% passando de 1.858 .959 para 1.791 .559 hectares (SOS MATA ATLÂNTICA, INPE, ISA, 1998:39 e 49). Entre os anos de 1995 e 2000, os avanços tecnológicos no campo do geoprocessamento permitiram ampliar a escala de estudo de 1:250.000 para 1:50.000. Isso possibilitou a identificação de fragmentos florestais de até 10 hectares, sendo que, pela metodologia empregada no levantamento realizado entre 1990 e 1995, só era possível contabilizar as áreas com mais de 25 hectares de extensão. Com essa mudança, o total do território coberto pela Mata Atlântica no Estado de São Paulo, que em 1995 era de 1.791.559 hectares, passa para 3.046.341 hectares (SOS MATA ATLÂNTICA, INPE, 2002:s/p). Entretanto, o mesmo estudo revelou também que a cobertura Atlântica continua em declínio. Ao final da década restavam em São Paulo 2.995.883 hectares, o que significa que, em cinco anos, a área coberta por este bioma teve uma redução de $15,25 \%$ para $14,94 \%$ (SOS MATA ATLÂNTICA, INPE, 2002:s/p.).

Apesar da redução da área total de Mata Atlântica, a análise em escala municipal revela situações muito heterogêneas. Com base nos dados da Fundação SOS Mata Atlântica, INPE e ISA (SOS MATA ATLÂNTICA, INPE, 1998), dos 622 municípios paulistas localizados no domínio da Mata Atlântica, entre 1990 e 1995, 310 municípios perderam cobertura florestal e 228 mantiveram suas áreas inalteradas. Entretanto, 85 municípios tiveram um saldo positivo de Mata Atlântica, isto é, o aumento da cobertura florestal superou a diminuição. Entre perdas e ganhos, estes 85 municípios ampliaram em 13.947 hectares a área total de Mata Atlântica, totalizando 0,8\% de incremento.

No período seguinte, entre 1995 e 2000, 270 municípios tiveram saldo negativo de Mata Atlântica, 244 mantiveram a mesma área e em 131 municípios - sendo 112 rurais, 10 ambivalentes e nove urbanos ${ }^{3}$ - o aumento foi maior do que a redução. Nesses 131 municípios o saldo

\footnotetext{
${ }^{3}$ Segundo tipologia proposta por VEIGA, et al. 2001:10-19 e VEIGA, 2002:33-34.
} 
positivo totalizou 23.048 hectares de incremento, ou 0,8\% da área total de Mata Atlântica no estado ${ }^{4}$.

O elevado número de municípios que mantiveram inalteradas as áreas de Mata Atlântica não deve ser interpretado, necessariamente, como um resultado favorável. O que se pode observar é que, em certos casos, a manutenção dessas áreas decorre de iniciativas que contribuíram para a sua conservação, contudo, na maioria dos municípios, as áreas de remanescentes florestais já eram irrisórias e mantiveram-se nos mesmos patamares.

O aumento da Mata Atlântica em cerca de 200 municípios também deve ser analisado com cautela, pois a ampliação da área não significa que a Mata tenha readquirido suas características e funções originais. É comum a existência de "florestas vazias", isto é, aquelas nas quais a fauna desaparece, geralmente devido à caça, e muitas espécies da flora deixam de ser polinizadas. A excessiva fragmentação florestal pode levar à quebra do chamado "fluxo gênico" e o isolamento de algumas espécies da flora ou da fauna amplia as possibilidades de relacionamentos endogâmicos e, conseqüentemente, seus efeitos deletérios. Outro problema é o "efeito de borda”, isto é: as bordas florestais estão mais sujeitas à degradação pela perda de umidade, pela ação do fogo, pela presença do gado ou de plantas forrageiras (PÁDUA, 2001:17-19).

Apesar dessas ponderações, não deixa de ser inusitado o fato de tantos municípios terem ampliado suas áreas de Mata Atlântica na década passada. Os principais motivos que explicam esse aumento sugerem respostas que não chegaram a ser previstas como hipóteses deste estudo. De fato, como suposto inicialmente, em 38\% dos municípios que tiveram aumento entre 1990 e 1995 e em 39,7\% dos que ampliaram a cobertura florestal Atlântica entre 1995 e 2000 prefeitos e gestores municipais consideram o avanço dos empreendimentos que valorizam o patrimônio natural como um dos determinantes da recuperação das matas. Nos demais municípios, todavia, predominam outras explicações, tais como: (1) o cumprimento da legislação ambiental decorrente da fiscalização mais intensa; (2) os projetos de reflorestamento com

\footnotetext{
${ }^{4}$ Apesar do aumento de 13.947 hectares (1990-1995) para 23.048 hectares (1995-2000) - atribuído à mudança da metodologia de análise -, proporcionalmente o total de incremento nos dois períodos analisados manteve-se em $0,8 \%$ do total da área de mata.
} 
espécies nativas; (3) a existência de unidades de conservação; (4) a retração das atividades agropecuárias; (5) e a conscientização de empreendedores e da população em geral.

\subsection{Razóes para o aumento da Mata Atlântica}

A pressão antrópica e o avanço da agricultura moderna são, geralmente, os principais responsáveis pela degradação das florestas. Poderse-ia supor, então, que o aumento da Mata Atlântica na década passada decorre de um esvaziamento populacional nos municípios paulistas que se tornaram mais verdes. Entretanto, não há qualquer evidência de que o incremento florestal esteja relacionado à redução da população. Ao contrário, dos 204 municípios com aumento de mata, 169 tiveram concomitante crescimento populacional. E muitos dos que mais reduziram suas populações também diminuíram a cobertura florestal durante a década passada.

No setor agropecuário, poder-se-ia imaginar que o notável avanço da agricultura orgânica teria influenciado a recuperação da Floresta Atlântica, pois esses agricultores são bem mais cuidadosos com o ambiente do que os chamados convencionais. De fato, os sistemas orgânicos de produção ajudam a manter a cobertura florestal já existente, reduzem as externalidades negativas e ampliam a diversidade biológica. Todavia, a área ocupada por estes sistemas produtivos no Estado de São Paulo é irrisória e não há qualquer indício de que essas unidades produtivas tenham contribuído para a ampliação da Floresta Atlântica.

Descartadas estas duas possibilidades, iniciou-se a investigação da hipótese segundo a qual em muitos municípios paulistas o aumento da Mata Atlântica decorre da crescente percepção dos agentes econômicos de que o custo de oportunidade da conservação das florestas e do patrimônio natural começa a se tornar mais vantajoso. Isto é, em determinadas situações, vale mais a pena explorar as vantagens que provêm dos atrativos naturais preservados, do que suprimi-los para dar lugar a outras atividades.

Pelo menos quatro evidências confirmam essa hipótese. A primeira é a de que em 75 municípios rurais e ambivalentes, dentre 180 analisados, prefeitos, técnicos e gestores consideram o avanço dos empreen- 
dimentos que valorizam o patrimônio natural como um dos responsáveis pela recuperação da Floresta Atlântica na década passada. Mesmo que se considerem as diferenças entre os informantes, não deixa de ser significativo o fato de que, espontaneamente, quase a metade dos entrevistados consideram esses empreendimentos importantes para a recuperação florestal.

A segunda evidência é a recuperação da Floresta Atlântica nas estâncias turísticas e nos municípios que integram os pólos de ecoturismo, locais onde tendem a se concentrar empreendimentos mais comprometidos com a conservação do patrimônio natural. No início da década de 1990 a maioria das estâncias balneárias, climáticas, hidrominerais e turísticas, assim como os municípios localizados nos pólos de ecoturismo, não conseguiram manter ou ampliar suas florestas. Da lista de 85 municípios paulistas que aumentaram as áreas de Mata Atlântica entre 1990 e 1995, apenas 20 são pólos, estâncias ou ambos. No geral, as 61 estâncias tiveram uma redução de 2.028 hectares de Floresta Atlântica e o saldo geral (diferença entre incremento e decremento) só foi positivo devido ao significativo aumento de 5.360 hectares no município de Iguape, na região do Vale do Ribeira. Já os 66 municípios localizados nos pólos ecoturísticos tiveram um saldo negativo de 9.530 hectares de Mata Atlântica.

Isso não significa, obviamente, que o aproveitamento econômico do patrimônio natural e das amenidades rurais seja responsável pela degradação florestal. Ao contrário, em várias estâncias e municípios ecoturísticos visitados, as iniciativas governamentais e o conjunto de empreendimentos que dependem diretamente do patrimônio natural nitidamente contribuíram para sua conservação. Mesmo assim, na primeira metade da década, as atividades que degradavam o ambiente superavam as atividades capazes de promover a sua conservação.

Entre os anos de 1995 e de 2000 a situação começava a mudar. Apesar das diferenças na metodologia de contagem dos remanescentes florestais utilizada nos dois períodos, verifica-se tanto nas estâncias turísticas como nos pólos de ecoturismo que o saldo de Mata Atlântica foi positivo. Nas 61 estâncias turísticas o aumento totalizou 1.907 hectares e nos 66 municípios localizados nos pólos ecoturísticos as áreas de mata foram ampliadas em 1.942 hectares. 
As investigações de campo também mostraram que, dentre os municípios que tiveram aumento de cobertura florestal na década passada, há vários que não são estâncias e não pertencem aos pólos ecoturísticos, mas que, progressivamente, ampliaram o conjunto de atividades voltadas ao aproveitamento das amenidades rurais: chácaras de lazer, segundas residências e outras atividades ligadas ao turismo rural.

A terceira evidência é a de que em três dos dez municípios rurais e ambivalentes com maior densidade de microempresas ou empresas de pequeno porte do estado - Águas de São Pedro, Águas de Lindóia e Serra Negra - a concentração de empreendimentos está diretamente relacionada ao aproveitamento das amenidades rurais. Em outros quatro municípios desta lista - Morungaba, Juquitiba, Dourado e Campina do Monte Alegre - grande parte das empresas constituídas recentemente segue nessa mesma direção. Nestes sete municípios há fortes indícios de que os agentes econômicos já começam a enxergar a conservação da natureza como um importante diferencial competitivo e de que o custo de oportunidade de conservação das matas começa a se tornar mais vantajoso.

A quarta evidência é a existência de nítidos arranjos locais em torno do aproveitamento das amenidades rurais. Isso ocorre na região conhecida como Circuito das Águas, na região das Cuestas e também na Serra da Mantiqueira. Coincidentemente, cinco dos dez municípios rurais e ambivalentes com mais elevada densidade de pequenos empreendimentos fazem parte dessas regiões (Águas de Lindóia, Águas de São Pedro, Dourado, Morungaba e Serra Negra). Nestes três arranjos locais concentram-se empreendedores cujos negócios são direta ou indiretamente relacionados a atividades de turismo e de lazer, os quais têm grande dependência do patrimônio natural conservado.

Nos municípios localizados no Circuito das Águas, nas Cuestas e na Mantiqueira e, também, nas estâncias turísticas e nos pólos ecoturísticos há nítidos sinais de que a manutenção e a regeneração das matas para aproveitamento das amenidades rurais começam a se tornar mais favoráveis do que a sua exclusão. Entretanto, o avanço dos empreendimentos que valorizam o patrimônio natural e promovem a sua exploração econômica não é a única explicação para a recuperação da Mata Atlântica, nem tampouco a mais relevante. Nos dois períodos analisados (1990-1995 e 1995-2000) o cumprimento da legislação ambiental, 
decorrente da fiscalização mais rigorosa, foi apontado como o principal determinante pela maioria dos prefeitos e gestores municipais entrevistados. As limitações impostas pelo estado à derrubada das matas, à eliminação das capoeiras ou ao plantio em áreas de preservação permanente (topos de morros, encostas, beiras de rios) e o fortalecimento das organizações governamentais responsáveis pelo cumprimento dessas limitações já começam a surtir evidentes efeitos práticos.

A recomposição natural decorrente, em grande parte, da retração das atividades agropecuárias também pode ser apontada como um dos principais determinantes que explicam o aumento da Mata Atlântica paulista na década passada. Esta explicação é mencionada por aproximadamente $30 \%$ dos gestores dos municípios que tiveram aumento da cobertura florestal na primeira metade da década de 1990 e por $43 \%$ dos analisados na segunda metade. Contudo, há claros sinais de que a maioria dos entrevistados subestima a importância deste determinante para a recuperação da Floresta Atlântica. E o motivo é bastante simples: os demais determinantes analisados (a fiscalização e o cumprimento da lei, os projetos de reflorestamento, as melhorias na gestão das unidades de conservação, os projetos e programas de educação ambiental) decorrem, essencialmente, de iniciativas das prefeituras ou de órgãos do governo estadual. A maioria dos entrevistados pertence a esses órgãos e é natural que busquem explicações para a recuperação florestal nas iniciativas das quais participam ou sobre as quais têm mais conhecimento. A regeneração natural das florestas nativas decorrente da evasão populacional ou da retração das atividades agropecuárias não é resultado de ações planejadas e não tem atores principais. Ela simplesmente ocorre e, na maioria dos casos, sem o conhecimento do poder público.

O cumprimento da legislação ambiental, decorrente da fiscalização mais rigorosa, e a regeneração natural das matas podem ser considerados os principais determinantes da recuperação florestal paulista na década passada. Em um grupo intermediário enquadram-se determinantes tais como: os projetos estatais de reflorestamento, a maior efetividade das unidades de conservação e, como suposto inicialmente, o avanço dos empreendimentos que valorizam o patrimônio natural e as amenidades rurais. Por fim, há um grupo de determinantes menos 
relevantes no qual se incluem: a educação ambiental e a preocupação com a manutenção dos recursos hídricos.

A constatação de que o avanço dos empreendimentos que valorizam o patrimônio natural não é o principal motivo que explica a recuperação da Floresta Atlântica em cerca de 200 municípios paulistas na década passada não reduz a importância deste determinante. Ao contrário, ficou evidente que, nos anos 1990, esses empreendimentos se espalharam por várias partes do estado, tornando-se importantes aliados do poder público na conservação da natureza. Pode-se mesmo supor que o crescimento das atividades econômicas que dependem dos atrativos naturais permitirá reduzir, ou mesmo substituir, os mecanismos estatais de comando e controle, como a fiscalização ambiental. Como mostra Elinor Ostrom (OSTROM, 1990), os usuários que dependem de um recurso de uso comum são os principais interessados em promover o manejo durável desse recurso.

É certo que não se pode fazer qualquer tipo de generalização, mas a incorporação das variáveis ambientais pelo ambiente econômico é tendencial e não ocorre de uma só vez. Muitos empreendedores não aderem aos esforços conservacionistas (free-riders), mesmo se aproveitando dos benefícios gerados pela manutenção do patrimônio natural e das amenidades rurais. Descarta-se, portanto, a noção de que uma hipotética consciência ecológica levará os agentes econômicos a uma repentina mudança de comportamento. Em verdade, é a lógica econômica que se sobrepõe às restrições ecológicas e não o contrário (ROMEIRO e SALLES FILHO, 2001:103). Por isso, mudanças em escala significativa só deverão ocorrer quando os agentes julgarem que a conservação da natureza pode se tornar um importante diferencial competitivo. E só serão duradouras se o custo de oportunidade for favorável, isto é, se o valor auferido pela manutenção do patrimônio natural conservado superar o valor que poderia ser obtido com outro tipo de atividade.

O que permanece incerto são as políticas e as ações que permitirão estimular a sinergia entre conservação e empreendedorismo, pois não existem fórmulas facilmente generalizáveis. O que se conclui a partir das experiências bem sucedidas é que essa desejável combinação não surgirá de iniciativas isoladas do estado nem, tampouco, de uma repentina regulação do mercado. As soluções devem vir de intervenções 
que ajudem a tornar o custo de oportunidade da conservação ambiental cada vez mais favorável.

As evidências reunidas na pesquisa, cujas conclusões são resumidas neste artigo, também mostram que a organização social desempenha um papel crucial na formação de arranjos institucionais mais favoráveis ao empreendedorismo e à conservação. Isso fica evidente nos municípios localizados nas regiões do Circuito das Águas, Cuestas e Serra da Mantiqueira, nos quais nítidos arranjos locais se formaram em torno do aproveitamento das amenidades rurais. O relacionamento entre representantes de empresas, de órgãos do governo e de organizações do terceiro setor tem estimulado ações cooperativas voltadas à conservação.

Em maior ou menor grau, os órgãos governamentais municipais e estaduais que atuam na região das Cuestas, no Circuito das Águas e na Serra da Mantiqueira interagem entre si formando redes de relacionamentos em torno de objetivos comuns. As empresas privadas também mantêm relações de concorrência e de cooperação e articulam-se em redes de relacionamentos com organizações do terceiro setor, com universidades e com órgãos estatais, com efeitos favoráveis para a competitividade de seus territórios. Há, portanto, fortes razões para se afirmar que nas regiões do Circuito das Águas, das Cuestas e da Serra da Mantiqueira formam-se arranjos locais em torno do aproveitamento das amenidades rurais, especialmente, das atividades turísticas.

\section{Conclusão}

Como se viu em Brotas, e em outros municípios localizados no Circuito das Águas, Cuestas e na Serra da Mantiqueira as vantagens comparativas decorrentes dos atributos naturais ou culturais são cruciais. Nesses territórios a ebulição empreendedora está diretamente relacionada às atividades que promovem o aproveitamento econômico dessas amenidades. Neles os novos empreendimentos e as oportunidades de trabalho são criados em função da possibilidade de um relacionamento mais próximo à natureza. São, portanto, territórios que estão conseguindo se aproximar de um estilo de crescimento muito menos destrutivo e, provavelmente, muito mais duradouro. 
Todavia, ficou evidente, também, que esta desejável combinação depende, muito mais, da existência de arranjos institucionais entre os atores sociais que interagem nestes territórios do que da existência de atributos naturais. São esses arranjos que propiciam condições mais favoráveis a empreendimentos inovadores e que ampliam os mecanismos de controle sobre os recursos de uso comum. As vantagens que decorrem das relações sociais são, portanto, muito mais decisivas do que as provenientes dos atributos naturais ou culturais.

São as relações sociais que estimulam ações cooperativas, permitindo valorizar os atributos do ambiente para que ele sirva de base a novos empreendimentos. Fica evidente, portanto, que a combinação entre empreendedorismo e conservação da natureza dificilmente ocorrerá na ausência de condições institucionais favoráveis, sejam estas criadas pelas organizações públicas, privadas, do terceiro setor, ou pela combinação de esforços de todas elas.

É certo que as situações verificadas nas regiões do Circuito das Águas, Cuestas e da Serra da Mantiqueira não constituem uma espécie de "modelo", o qual pode ser facilmente multiplicado em qualquer parte do estado. Ainda assim, há fortes evidências de que a instalação de mecanismos participativos de planejamento e de gestão, a clara definição de direitos de propriedade e o estabelecimento de regras de uso dos recursos naturais ajudam a fortalcer as relações de confiança entre os indivíduos e as organizações, criando um ambiente instucional mais favorável ao empreendedorismo e à conservação.

Essas relações de confiança não dependem necessariamente de heranças culturais acumuladas durante séculos, por várias gerações. Como se viu no caso de Brotas e demais municípios da região das Cuestas, as relações de confiança podem ser construídas por atores sociais que partilham dos mesmos projetos, das mesmas identidades e vocações.

\section{Referências Bibliográficas}

CONCEIÇÃO, Otavio. Instituições, crescimento e mudança na ótica institucionalista. Tese de doutorado apresentada ao Departamento de Economia/UFRS, Porto Alegre, 2000. 
EHLERS, Eduardo. Determinantes da recuperação da Mata Atlântica no Estado de São Paulo. Tese de Doutorado orientada por José Eli da Veiga, São Paulo: Programa de Pós-Graduação em Ciência Ambiental/USP, 2003.

KUHN, Thomas. A estrutura das revoluções científicas. São Paulo: Perspectiva, 1995 [1962] (Tradução: Beatriz Vianna Boeira e Nelson Boeira).

KUTTNER, Robert. Tudo à venda - as virtudes e os limites do mercado. São Paulo: Companhia das Letras, 1998.

NORTH, Douglass. Structure and change in economic History. New York: W.W. Norton \& Company, 1981.

. Institutions, institucional change and economic performance. Cambridge: Press Syndycate of the University of Cambridge, 1990.

OCDE (Organization for Economic Cooperation and Development). Fostering entrepreneurship. Paris: OCDE, 1998.

OSTROM, Elinor. An agenda for the study of institutions. Public Choice. 48 (1), pp.3-25, 1986.

. Governing the commons: the evolution of institutions for collective action. Cambridge: Cambridge University Press, 1990.

. Reformulating the commons. Joana BURGER et al.. Protecting the commons - a framework for resource management in the Americas. Washington, DC: Island Press, pp.17-41, 2001.

PÁDUA, Claudio. Aspectos básicos da biologia da conservação aplicáveis à Mata Atlântica. André LIMA. Aspectos jurídicos da proteção da Mata Atlântica. Documentos ISA 7, São Paulo: ISA, pp. 16-21, 2001.

PORTER, Michael E.. A vantagem competitiva das nações. Rio de Janeiro: Campus, 1989 (Tradução: Waltensir Dutra).

ROMEIRO, Ademar Ribeiro e Sergio SALLES FILHO. Dinâmica de inovações sob restrição ambiental. Ademar Ribeiro ROMEIRO; Bastiaan 
Philip REYDON e Maria Lúcia Azevedo LEONARDI (org.). Economia do meio ambiente. Campinas: UNICAMP/IE, pp.85-124, 2001.

SCHUMPETER, Joseph. A teoria do desenvolvimento econômico. Rio de Janeiro: Fundo de Cultura, 1961 [1934] (Tradução de Laura Schlaepfer).

SOS Mata Atlântica e INPE (Instituto Nacional de Pesquisas Aeroespaciais). Atlas dos remanescentes florestais da Mata Atlântica período 1995-2000. Relatório final, São Paulo: 2002.

SOS Mata Atlântica; INPE (Instituto Nacional de Pesquisas Aeroespaciais) e ISA (Instituto Socioambiental). Atlas da evolução dos remanescentes florestais e ecossistemas associados no domínio da Mata Atlântica no período 1990-1995. São Paulo: s./e., 1998.

VEIGA, José Eli. Biodiversidade e dinamismo econômico. Anais do $\mathbf{2 8}^{\mathbf{0}}$. Encontro Nacional de Economia. Campinas: 12-15 de Dezembro de 2000. Anais em CD-ROM.

Cidades imaginárias - 0 Brasil é menos urbano do

que se imagina. Campinas: Autores Associados, 2002.

VEIGA, José Eli et al.. O Brasil rural precisa de uma estratégia de desenvolvimento. Brasília: Convênio FIPE - IICA (MDA/CNDRS/ NEAD), 2001.

Recebido em abril de 2005 e revisto em agosto de 2006. 